\title{
Public sector monitoring and evaluation in the Fourth Industrial Revolution: Implications for Africa
}

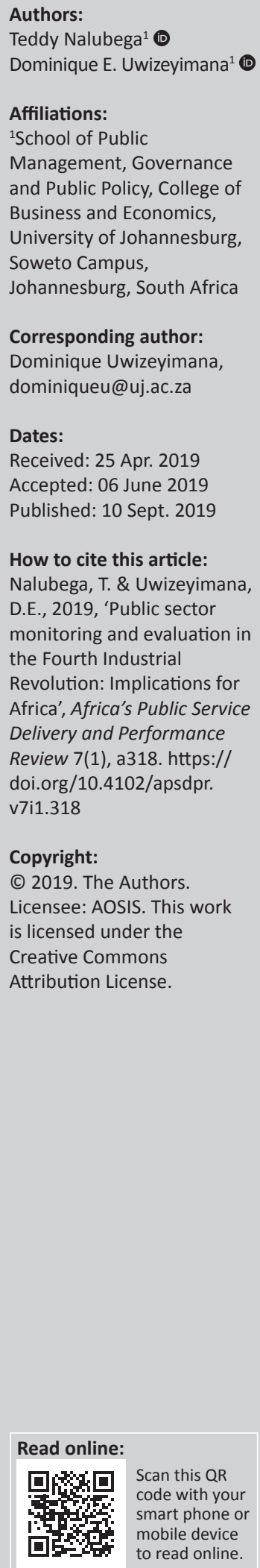

Background: The current era of transformative scientific and technological advances is reshaping traditional government business as it is blurring geographical boundaries and posing a challenge to existing regulatory frameworks.

Aim: This article explores the implications of the Fourth Industrial Revolution (4IR) on current public sector monitoring and evaluation (M\&E) in Africa.

Setting: The 4IR (also called Industry 4.0) is thought to bring about enormous benefits associated with increased efficiency and effectiveness in service delivery. However, even with the highly anticipated opportunities related to automated and digital transformations in the $4 \mathrm{IR}$, governments in African countries need to understand the challenges ahead and will need to measure and mitigate the impact of the unpredictable and rapidly changing products and services created for the public.

Methods: Using the documentary review method to collect data, this research answers the following guiding questions: (1) How has the 4IR been harnessed in Africa to improve public sector service delivery? (2) How can the 4IR be harnessed to improve M\&E in the public sector in Africa? and (3) What are the implications of the 4IR technologies on public sector M\&E in Africa?

Results: Findings reveal that various 4IR disruptive technologies have already been fully adopted in public service delivery in Africa. The 4IR disruptive technologies have the capacity to capture or collect and analyse multi-dimensional information or data from multiple contextual variables, with minimal costs and time in both qualitative and quantitative formats. However, findings disclose that the use of big data in evaluation requires extra new skills training and critical discussions among M\&E specialists, technologists, economists, engineers and tech companies as a whole so as to significantly enhance the quality, validity and reliability of the data captured by the technologies.

Conclusion: Deep integration, collaboration and embracing change are needed to efficiently manage and control the multi-stakeholder nature of the 4IR innovative technologies. This article asserts that policies on the 4IR technologies need to be adaptive, inclusive, sustainable and human centred in order to efficiently regulate or guide these innovative technologies without curtailing the future opportunities.

Keywords: Fourth industrial revolution; 4IR; public policy; monitoring and evaluation; public sector management; Africa.

\section{Introduction}

The Fourth Industrial Revolution (4IR) is challenging traditional management and governance norms in the public and private sector globally. The innovations and technological advancements of the 4IR are uprooting and changing how societies normally do business and go about their daily work (World Economic Forum [WEF] 2017:6). These innovations and technological advancements have been referred to as a set of disruptive technologies 'that are transforming social, economic, and political systems, and putting pressure on leaders' and policy-makers globally (WEF 2017:6).

African countries are already witnessing the innovations brought forth by the 4IR, and many have appreciated the ability of the designed tools to solve various societal challenges. In Rwanda in 2016, Zipline (an American company that designs and tests drone technology) launched the first initiative in the world using drones to deliver blood for blood transfusions, which decreases the time for patients in rural areas who are challenged by the terrain and infrastructural gaps to 
receive blood (Zipline n.d.). The services provided by the drones have scaled up from delivering critical medical products to emergency vaccines and life-saving medicines (Zipline n.d.). The Rwandan government has since established partnerships to set up a centre for the Internet of Things (IoT) to facilitate students in experiencing and developing IoT prototypes and conduct academic research in this field (Republic of Rwanda 2016). The Nigerian company Hello Tractor uses the Global Positioning System (GPS) to connect farmers to tractor services near them for a fee, an initiative that has helped farmers plant and harvest on time (Hello Tractor 2019). Ghana's Farmerline uses mobile technology to help connect farmers to information and vital services such as financial literacy education, weather forecasts, and market prices, all in local languages, to help farmers in Ghana to access quality farm inputs and earn more for their produce (Farmer line n.d.).

Financial Technology (Fintech), the use of technology in financial services, has tremendously reduced costs and increased the efficiency of financial services by allowing urban and rural customers to flexibly and in real time transact and interact with their financial service providers (Centre of Excellence in Financial Services 2018:2). The year 2007 saw the launch of M-Pesa in Kenya, a mobile phone-based money transfer, financing, and microfinancing service that provides people in rural and urban areas with formal financial systems. It also reduces crime and petty corruption, which are largely cash based (Vodafone 2017; Yesmin, Paul \& Udin 2019:131). M-Pesa has been adopted by other countries such as South Africa, Tanzania, Lesotho, Mozambique, Egypt, Ghana, Afghanistan, India, Romania and Albania, and they have enabled customers in rural and urban areas to safely and securely send, receive and store money via a basic mobile phone (Sethi 2017; Vodafone 2017). Banking applications (apps) have been developed to 'allow consumers to use their mobile phones for bank-to-bank electronic fund transfers payments, bill payments, and pre-paid purchases' (Centre of Excellence in Financial Services 2018:24). In South Africa, a pan-African Fintech company, MyBucks, was founded in 2011, and in 2016, this company was listed on the Frankfurt Stock Exchange in Germany (Nsehe 2016). MyBucks, the first Fintech business in Africa, currently offers a broad portfolio of virtual banking products in not only African countries but also in Europe and Australia. MyBucks utilises credit technology, supported by an in-house artificial intelligence (AI) team and FinCloud software to determine the credit history and creditworthiness of consumers (Nsehe 2016).

While the 4IR clearly presents various opportunities with regard to timely and less costly services, it also poses challenges to the existing regulatory frameworks of African countries, especially in the spheres of 'data security, cyber security, consumer protection, and laws on technology use' (Martin 2019:1). The increasing global interconnectivity and complexity call for critical research and analysis on the consequences of the 4IR for public sector monitoring and evaluation (M\&E) in Africa. Hence, the article presents a discussion on how public sector M\&E in Africa will be affected by the $4 \mathrm{IR}$.

The discussion in this article results from a perceived need to improve the status of public sector M\&E in Africa by taking advantage of the opportunities presented by the 4IR. The citizens and many politicians in Africa in recent years have increasingly been demanding evidence-based decisionmaking, which has reduced civil servants to merely monitoring and evaluating the development interventions for simply compliance reasons (Wotela 2017:1). The prevailing literature points out the concern of lack of capacity of African evaluators and policy-makers to make meaning of and use the evaluation recommendations (Basheka \& Byamugisha 2015:76; Goldman et al. 2018:2; Uwizeyimana \& Basheka 2017:24). Goldman et al. (2018:10) noted that government evaluation systems in Africa tend to focus more on the monitoring part and less on the evaluation side because of the punitive approach employed during evaluation. The punitive approach has in turn hindered learning from the findings because of the high tension it builds around the concerned officers, hence less follow-up on the evaluation recommendations (Goldman et al. 2018:10). The lack of appropriate capacity and approach for evaluation in Africa is discussed to be as a result of the complex evaluation models packed with theories and practices originating from foreign or western countries with less customisation to the African setting (Basheka \& Byamugisha 2015:79; Cloete 2016:56). These challenges had been noted to originate from the fact that $M \& E$ was a young discipline and practice with a limited number of professionals in the field (Basheka 2016:96; Cloete 2016:61). A number of universities and other tertiary institutions have developed M\&E programmes and are continuously producing M\&E graduates, but there is still is a wide mismatch between the supply and demand of evaluation professionals in Africa (Basheka \& Byamugisha 2015:91; Basheka, Lubega \& Baguma 2016:72). Short-training M\&E programmes are also increasingly being offered by various training institutions to match the demand created by the political weight on the accountability and transparency of public funds (Wotela 2017:2). Cloete (2016:61) pointed out that another major problem in Africa is the lack of visibility of African evaluators' profiles because they do not write enough about evaluation for public consumption. Studies have also indicated that there is a lack of resources for the limited number of evaluation scholars to travel to international conferences and other events, which limits their international competitiveness (Basheka \& Byamugisha 2015:87; Cloete 2016:61).

Monitoring and evaluation in the public sector, as part of public administration and higher-order management function, has the potential to evolve and adapt to the changing environment while addressing public demands (Uwizeyimana \& Basheka 2017:30). This calls for improvement of the intellectual abilities of evaluation scholars and practitioners to utilise the available opportunities presented in the technological innovations to develop practical, suitable 
and sustainable solutions to $\mathrm{M} \& \mathrm{E}$ issues in the African context (Uwizeyimana \& Basheka 2017:30). The 4IR presents enormous opportunities for the customisation of M\&E into African-rooted policy, programme and project evaluation approaches.

\section{The Fourth Industrial Revolution in perspective}

The 4IR is 'a fusion of disruptive technologies that are blurring the lines between the physical, digital, and biological spheres' (WEF 2017:3). These fusions of disruptive technologies are mainly the transformative, scientific and technological advances presented in various fields such as advanced robotics, AI, drones, the IoT, wearables, additive manufacturing or three-dimensional (3D) printing, driverless cars, blockchain technologies, bioscience technologies, augmented reality (AR) and virtual reality (VR), to mention but a few, which are reshaping the way people live, work and relate to one another (WEF 2017:3; Xing \& Marwala 2017:11; Xing, Marwala \& Marwala 2018:171). The 4IR promises to bring about an age of abundance based on the predictions of it being one of the most disruptive and transformative eras in world history (Jarbandhan 2017:61; Xing \& Marwala 2017:11; Xing et al. 2018:172). This new era, to a great extent, threatens governments' operations ranging from defence and intelligence to public safety, agriculture, environmental protection and public transportation (Xing et al. 2018:173). It is therefore important that governments are armed with all the necessary intelligence to envision and enact bold policies in this techno-economic paradigm. However, to be able to prepare for and be able to cope with the $4 \mathrm{IR}$, it is important that deliberate efforts are made to understand the $4 \mathrm{IR}$.

In the 4IR, technology is not an innovation but rather a tool to deliver innovations with several driving forces (Deloitte 2017:4). The disruptive changes brought about by the $4 \mathrm{IR}$ have been projected to substantially impact on the traditional operations of businesses and interaction among humans in both the private and public sectors (Davis 2016; Xing et al. 2018:172). There are varied concerns about the kinds of trends and the impact that the 4IR will create for the labour market. The most common concern is technological progress that is feared to substitute human labour with machines, which could lead to technological unemployment (i.e. the loss of jobs caused by technological change), resulting in increased inequality in the short-term, regardless of the long-term beneficial effects (Mokyr, Vickers \& Ziebarth 2015:32; Xing et al. 2018:175). The McKinsey Global Institute (2017), however, clarified that:

\footnotetext{
... automation is not a new phenomenon, and fears about its transformation of the workplace and effects on employment date back centuries, even before the first Industrial Revolution [1IR] in the 18th and 19th centuries. (p. 3)
}

Technologists and economists have raised questions about the effects that AI will have on the nature of work and employment opportunities (Brynjolfsson \& McAfee 2014; Jarbandhan 2017:63). For example:
... in the 1960s, US President Lyndon Johnson paneled a National Commission on Technology, Automation, and Economic Progress whose conclusion, among others was the basic fact that technology destroyed jobs, but not work. (McKinsey Global Institute 2017:3)

Despite the negative concerns, Xing et al. (2018:174) believe that the new technologies introduced will always need humans to coordinate implementation tasks and perform maintenance duties. According to the most recent survey conducted by the WEF in 2016, the 4IR is to significantly impact on job creation and job displacement, heighten labour productivity and widen skills gaps (WEF 2017:13). According to this survey, a wide variety of jobs, not limited to a given geographical location, are likely to be created while more than 5 million jobs are likely to have been lost to disruptive labour market changes globally by 2020 (WEF 2017:13).

Unlike past industrial revolutions, the 4IR calls for deep integration and collaboration on long-term technology and capability development, and is globally focused (Davis 2016). During the 1IR, which was characterised by rapid industrialisation, the main innovations were mainly steam and water power, which replaced human and animal power with machines (Davis 2016; Jarbandhan 2017:62; Marwala \& Hurwitz 2017; Rifkin 2012; Xing \& Marwala 2017:11). These innovations started in Great Britain around the 1760s and then spread throughout continental Europe and the United States of America (USA). During the Second Industrial Revolution (2IR), which began in the 1850s, the main innovations were electricity, internal combustion engines, aeroplanes, telephones, cars, radio and mass manufacturing or production (Davis 2016; Gordon 2016; Jarbandhan 2017:62; Marwala \& Hurwitz 2017; Rifkin 2012; Xing \& Marwala 2017:11). The 2IR was marked by a transition of technological leadership from Britain to the USA and Germany. The first giant industrial corporations like US Steel, General Electric, Standard Oil and Bayer AG joined the railroad and ship companies in the 2IR. The Third Industrial Revolution (3IR), which is believed to have started in the 1950s, was characterised by the invention of electronics, the Internet and the use of information technology (IT) to automate mass production (Davis 2016; Gordon 2016; Jarbandhan 2017:62; Marwala \& Hurwitz 2017; Rifkin 2012; Xing \& Marwala 2017:11). The Internet, which was invented in the mid-1990s, and Marc Andreessen's Mosaic/Netscape system have led to faster growth rates of computing and IT (Kosner 2012). This further reduced the costs in generating and disseminating information and gave rise to Internet technology companies like Apple, Google, Amazon, Facebook and many others. According to Rifkin (2012), the 3IR led to the democratisation of information, energy, manufacturing, logistics and marketing highly required new high tech skills in IT and embedded computing, nanotechnology, sustainable chemistry to mention but a few. The discussion by Rifkin (2012) on the 3IR to a given extent makes it difficult to draw 
a clear line between the 3IR and 4IR. However, the discussion by Klaus Schwab, the founder of the World Economic Forum (WEF), explains that the 4IR is simply building on the 3IR (Schwab 2016).

The characteristics of the 4IR have not yet been fully defined and agreed upon by scholars in technical institutions of innovation. It is, however, described as a revolution driven by $\mathrm{AI}$ and cyber-physical systems characterised by digitalisation and the integration of vertical and horizontal value chains, the digitalisation of product and service offerings and digital business models and customer access (Davis 2016; Schwab 2016; Xing \& Marwala 2017:11). Thus, while in the 3IR 'government services [are] increasingly provided via electronic means (such as computers, mobile phones, etc.)' (Uwizeyimana \& Basheka 2017:9), the technological change in 4IR is driven by mobile Internet and cloud technology; crowdsourcing, the sharing economy and peer-to-peer platforms; advances in computing power and big data; AI and machine learning; advanced robotics and autonomous transport; the IoT; advanced manufacturing and 3D printing; new energy supplies and technologies; and advanced materials, biotechnology and genomics (Schwab 2016; WEF 2017:7; Xing \& Marwala 2017:10).

\section{Improving public sector service delivery through the Fourth Industrial Revolution}

In an attempt to improve public sector service delivery, some African countries adopted the use of 4IR technologies. Discussed below are some of the ground-breaking innovations in Africa.

\section{Use of drones to improve health care}

In 2016, Zipline launched in Rwanda the first initiative in the world of using drones to deliver blood (Zipline n.d.). In some parts of the country where it took an average of four hours to deliver life-saving blood and other medical supplies, the delivery period was reduced to $15 \mathrm{~min}$ (Nsengimana 2018). The drone, which is a combination of robotics and AI, has significantly transformed Rwanda's medical supply chain and saved many lives (Nsengimana 2018; Zipline n.d.). From the many success stories, Rwanda has since established partnerships to set up a centre for IoT to facilitate students in experiencing and developing IoT prototypes and conduct academic research in this field (Republic of Rwanda 2016).

In 2017, Tanzania, in partnership with Zipline, also launched the use of drone delivery services to provide emergency on-demand access to critical and life-saving medicines (Banker 2017; Zipline n.d.). Through the Tanzanian Ministry of Health and its national medical stores department, Zipline uses the drones to deliver on-demand blood transfusion supplies, emergency vaccines, HIV medications, antimalarials, antibiotics, lab reagents and other surgical supplies (Zipline n.d.).

\section{Using big data to respond to and contain the spread of epidemics in Senegal}

Ebola is a virus transmitted to people from wild animals and transmitted through human-to-human contact (World Health Organization [WHO] 2018). The control of Ebola outbreaks relies on efficient surveillance, early detection, tracing of patients' movement, isolation of patients, case management, good laboratory service and safe and dignified burial of the dead (WHO 2018). During an Ebola outbreak in Senegal in 2014, in order to trace the patients' movement, 'Orange Telecom handed over anonymized voice and text data from 150,000 mobile phones to Flowminder' (Wall 2014:1). Flowminder, a Swedish non-profit organisation, used these data to visualise the typical population movements of the Ebola patients in the region (Wall 2014). The visualised information provided people's real-time movements and was used by the authorities to decide on the best locations to set up treatment centres and to restrict travel to contain the disease (Wall 2014).

\section{Using intelligent robots to control road transport traffic in the Democratic Republic of the Congo}

The Democratic Republic of the Congo (DRC) was the first country in the world to use a robot in the human form of, for example, a police officer, to regulate traffic in the city in 2013 (Al Jazeera 2014). Giant, solar-powered robots ('robocops') are being used to control traffic in Kinshasa, DRC (Idowu 2018). This project was developed by Women's Technology Cooperative to solve the challenges of heavy traffic in the cities of the DRC and drivers who defy traffic rules (Agence France-Presse 2015). This arm-waving, periodically rotating robocop is equipped with cameras that can watch over the roads (Al Jazeera 2014). The robocop's frame is also fitted with green and red lights that control the traffic flow at crossroads, and the surveillance cameras in it record and send real-time images to police stations (Agence France-Presse 2015).

\section{Using mobile technology and the Global Positioning System to improve the agricultural sector}

Many governments in sub-Saharan Africa have for years been unable to adequately support agriculture producers to access relevant information so as to efficiently produce and meet the required agricultural standards and demand. Mobile technology has recently been adopted to support farmers. For example, in Ghana, Farmerline uses mobile technology to help connect farmers to information and vital services, which has helped many farmers to access quality farm input and earn more for their produce (Farmer line n.d.). In Kenya, since 2014, the provision of agricultural inputs on credit by One Acre Fund to smallholder farmers and digital loan repayments through M-Pesa have been reported as a successful initiative for fighting poverty and hunger in rural Kenya (Waldron \& Amusin 2017). Hello Tractor in Nigeria uses GPS to connect farmers to tractor services near them for a fee, which helps farmers to plant and harvest on time (Hello Tractor 2019). The full benefits 
of such initiatives in agriculture will, however, depend on the effectiveness of public-private sector collaborations.

\section{Using artificial intelligence and blockchain technologies to improve financial services}

In South Africa, MyBucks, the first Fintech business in Africa, is currently offering a broad portfolio of virtual banking products in not only African countries but also in Europe and Australia. This company utilises credit technology, supported by an in-house AI team and FinCloud software, to determine the credit history and creditworthiness of consumers (Nsehe 2016).

In 2014 in Kenya, a local mobile-based fresh produce supplier called Twiga Foods launched a pilot on the use of AI and blockchain technology to secure loans for vegetable vendors who subscribe to its produce delivery services (Twiga 2018a). Twiga Foods sources agricultural produce from its networkregistered farmers and delivers the produce to its networkregistered vendors (clients) in the marketplace, at a given price (Twiga 2018b). Twiga Foods uses blockchain technology to keep track of the transactions made by its clients and uses these data to assess their ability to access loans and other financial products.

\section{Using massive open online courses to improve access to education}

Massive open online courses (MOOCs) are described as a form of education where a course of study is made available freely online to many participants; however, no academic credit is offered (Xing \& Marwala 2017:12). In Africa, universities such as the University of Lagos, University of Cape Town, University of the Witwatersrand and Stellenbosch University are already offering MOOCs (MOOC List n.d.). As the MOOCs are offered online, the costs incurred in the physical building and instructors needed to accommodate and teach a huge number of students are eliminated (Xing \& Marwala 2017:12).

\section{Context of monitoring and evaluation in Africa}

Monitoring and evaluation can be described as a process that aims to continuously track programme, policy and project progress to systematically and objectively assess the status of the stated programme/policy/project towards the intended or desired results or goals. Monitoring helps in the regular tracking of the necessary information, which provides a basis for evaluation and learning in order to make timely decisions and ensure accountability.

The historical drivers of M\&E in Africa are discussed in order to better understand their current state in Africa (Auriacombe 2013:717; Basheka \& Byamugisha 2015:76). Monitoring and evaluation in Africa has historically been driven by global evaluation approaches, theories and practices that originated from the USA, Canada, Britain and Western Europe (Cloete
2016:56). Basheka (2012:31) argues that M\&E existed before colonialism when the pre-colonial African governments devised mechanisms for service delivery by the leadership. In the post-colonial era, M\&E started as a prerequisite for development aid and involved signing agreements that emphasised the adoption of those models and practices by the agencies or donor countries (Cloete 2016:57). The kind of aid offered was aimed at improving service delivery and the most prominent measures where $M \& E$ was required included public service reforms and poverty-reduction strategies that emphasised results and accountability (Kimaro, Fourie \& Tshiyoyo 2018:103; Morgan, Baser \& Morin 2010:31).

The systematic practice of evaluation was reported to have been started in Nairobi, Kenya, by a network of evaluation practitioners in 1977 whose main objective was to enhance capacity building for the United Nations Children's Fund (UNICEF) (Cloete 2016:58). Monitoring and evaluation systems have since been built at various levels in the public and private sectors of various African countries (Kimaro et al. 2018:105) and this growing practice has resulted in the registration of over 26 verified evaluation associations and networks in Africa (Cloete 2016:61). Many universities and other tertiary institutions in Africa currently offer M\&E as a stand-alone discipline of study (Basheka \& Byamugisha 2015:87-88; Uwizeyimana \& Basheka 2017:17). Monitoring and evaluation has been incorporated deeply into public administration and governance structures, although many evaluations are still commissioned by international donors or development agencies (Basheka \& Byamugisha 2015:90; Cloete 2016:61; Goldman et al. 2018:1: Kimaro et al. 2018:105). Monitoring and evaluation greatly facilitates the interactions between the government and its citizenry by providing relevant, accurate and timely information that could be used for improvement in the implementation of the public programs or projects (Basheka \& Byamugisha 2015:92; Kimaro et al. 2018:105).

Monitoring and evaluation systems have been adopted by different African governments, with Benin, Uganda and South Africa acknowledged for the faster implementation of their national evaluation systems (Goldman et al. 2018:1). These three countries have a national evaluation policy, with variations in the adopted methodology (Goldman et al. 2018:7). A national evaluation system is defined by Goldman et al. (2018:1) as 'a national system which guides how evaluations are selected, implemented and used'. Goldman et al. (2018:7) noted that there are challenges in ensuring the utilisation of evaluation findings for policy improvement and better implementation. The capacity system, as defined by Goldman et al. (2018:7), refers to 'being able to identify M\&E capacity weaknesses in the system, and then to address them'. Many countries still face challenges as a result of capacity weaknesses. Goldman et al. (2018:9) further reported that funding is a huge challenge and that the lack of evaluators and government staff in evaluation capacity affects the performance of the $M \& E$ functions in the respective countries. Earlier research by Basheka and Byamugisha (2015:91) 
indicated that there is a pool of M\&E professional graduates from universities and other tertiary institutions, but there is a 'mismatch between supply and demand of evaluation professionals'. The solution to these challenges lies in the ability of the various actors - bodies, governments, universities and other tertiary institutions, associations and networks - to sustainably harness existing internal synergies and exploit the opportunities presented by the prevailing technology (Basheka \& Byamugisha 2015:91).

\section{Improving monitoring and evaluation in the Fourth Industrial Revolution}

As noted, technological innovations in 4IR are driven by AI and machine learning; mobile phones and the Internet; the IoT and GPS devices; advanced manufacturing and 3D printing; new energy supplies and technologies; and advanced materials, biotechnology and genomics (WEF 2017:7; Xing \& Marwala 2017:10).

Some of these technologies have been used by countries in Africa to improve projects and programme delivery. The increased usage of these technologies is closely linked to the exponential growth of big data, which, if efficiently and strategically utilised, can aid in the identification of community needs, provision of timely signals and response to emergencies. Notably, these data can enhance the public sector M\&E in Africa if efficiently adopted and meticulously utilised. Many governments of African countries have been reported as having challenges in M\&E, especially in the data collection and evaluation capacity (Goldman et al. 2018:7). These technologies have the capacity to capture and collect multi-dimensional information or data from multiple contextual variables, with minimal costs and time, from a given population in both qualitative and quantitative formats. With such technologies, the analysis of data could be done much faster, and, coupled with mixed methodologies to improve the validity and reliability of the data, decisionmaking could be much faster.

The use of big data requires expertise to analyse, and therefore, it is important that resources are secured towards the training and education of key public officials in such critical areas. If not, how will governments know if the services offered to citizens are genuine and create a positive impact? How will the African governments minimise data exploitation of its citizens? Forming partnerships with tech companies for data management and analysis is the simplest strategy; however, if such partnerships are not well managed, they could result in a series of data-exploitation catastrophes. Such partnerships call for boards of public agencies to have a team of multi-disciplinary experts to assist in the complex information or data environment. If the tech company states that the process will be secure, it may not necessary imply that it will abide by the ethical values of the agency. The risks of the partnership are not only towards the agencies solely but also to the programme beneficiaries or clients or citizens.
Making decisions about other people's data without their involvement and consent would not be right in particular situations.

While adopting disruptive innovations to improve M\&E in the public sector in Africa, it is important to note that different countries in Africa have different capacities and critical needs and that their citizens have differing behavioural traits. Therefore, before adopting any digital or disruptive technology for a country, much effort must be put towards understanding the kind of communities (people) in the country, identifying the trends on how they interact and communicate daily, their capabilities and skills sets, and objectively predicting likely change in the future. With all these aspects well researched and documented, the right team must be put in place to implement, integrate and optimise the use of the correct disruptive technology for adoption in the country. Through all these endeavours, constant communication among the team must be ensured to achieve the objective of the innovative technology adopted.

\section{Artificial intelligence}

Artificial intelligence, or machine intelligence, is defined by Kaplan and Haenlein (2018:15) as 'a system's ability to correctly interpret external data, to learn from such data, and to use learnings to achieve specific goals and tasks through flexible adaptation'. Artificial intelligence has been described as the DNA of the 4IR by Marwala and Hurwitz (2017). According to Marwala and Hurwitz (2017), most of the work previously performed solely by the human will have a touch of AI in many aspects and will be monitored in real time. Recent research indicates that various machines can be equipped with intelligent robotics, sensors and mobile terminals to perform extraordinary tasks (Lakhiar et al. 2018:12). As presented above, the DRC is already using intelligent robots as police officers to regulate traffic. Xing et al. (2018:172) explain that using AI has the ability to generate over 100 gigabytes of data within a second. With the ability to analyse the big data generated by AI, new insights and discoveries can lead to new developments, growth and transformation (Xing et al. 2018:172). Recent studies have indicated that AI has significant potential and capacity to improve agricultural productivity and health care systems when employed in various roles previously performed by humans (Lakhiar et al. 2018:12). Having such innovations employed in the public sector can immensely advance service efficiency while simultaneously storing data that can be analysed to make decisions for further improvements and learning.

\section{Blockchain technology}

Blockchain technology is a decentralised, distributed and public digital ledger that is used to record transactions across many computers so that any involved record cannot be altered retroactively without the alteration of all subsequent blocks (Peck 2017:26; Rifi et al. 2018:2; Zheng et al. 2019:6). A blockchain can be compared to a log with 
records batched into time-stamped blocks, with each block identified by its cryptographic hash (\#), hence establishing a link between the blocks with easy access to information on that network, such as identity certificates and transaction content (Rifi et al. 2018:2; Zheng et al. 2019:6). Such technology allows participants to verify and audit transactions independently and relatively inexpensively (Zheng et al. 2019:6).

Blockchain technology can be incorporated in agencies' accounting and record-keeping procedures to create permanent, public and transparent ledgers of payments made, without sacrificing autonomy and running the risk of exposing sensitive data to the public via the Internet. As presented above, Twiga Foods in Kenya uses blockchain technology to assist in securing loans for its customers. Using blockchain technology can aid in solving the longstanding problem of double-spending as it can confirm that each unit of value was transferred only once (Peck 2017:27; Rifi et al. 2018:2; Zheng et al. 2019:6). A private blockchain can be adopted, where one is invited by the network administrator. In such an arrangement, the participant's access and the validator's access are restricted. A consortium blockchain technology can also be adopted if there is a need to restrict users' reading rights. When a blockchain technology is properly set up to detail an exchange agreement, it can provide a record that compels offer and acceptance. Some African countries like Uganda, South Africa and Kenya have already officiated the use of blockchain technology with the aim of improving service delivery and the promotion of transparency.

\section{Virtual reality technology}

Virtual reality technology creates a realistic 3D image or artificial environment by means of hardware and software that are capable of convincing the human brain that it is somewhere it is really not. It can be a cost-effective tool for social or scientific research to study, monitor and evaluate the interaction of various elements in a controlled environment.

Virtual reality is described as an interactive computergenerated experience, used to generate realistic images, sounds and many other sensations, taking place within a simulated environment. In VR, the user can be fully immersed, semi-immersed or non-immersed in a fully artificial digital environment. The other forms of VR include $\mathrm{AR}$ and mixed reality (MR).

Augmented reality blends what the user sees in their real surroundings with digital content generated by computer software. In AR, the virtual objects are overlaid on the realworld environment. Mixed reality or hybrid reality merges the real and virtual worlds to produce new environments and visualisations where physical and digital objects co-exist and interact in real time. In MR, the virtual objects are anchored to real-world objects and the user is therefore allowed to interact with combined virtual and real objects.

\section{Drones}

An unmanned aerial vehicle, or drone, is an aircraft operated by a ground-based controller with a system of communications between the two. A drone has the capability to fly at relatively low heights, and therefore, it can be employed to perform various tasks in different sectors like agriculture, health, security, disaster relief, aerial surveillance, cargo transport, scientific research and so on (Floreano \& Wood 2015:460; Marín et al. 2018:2). As discussed, Rwanda already uses drones to deliver, for example, emergency medical supplies. Drones can be employed to monitor game parks, large-scale agricultural plantations and construction works in real time; however, they pose privacy, safety and security concerns.

\section{Internet of Things technology}

The IoT is described as the extension of Internet connectivity into physical devices that are embedded with electronics and other forms of hardware that enable these devices to communicate and interact with others via the Internet (Vermesan et al. 2013:8). This implies that IoT devices can be remotely monitored and controlled. The application of IoT devices is diverse as they can be tailored to different needs. The IoT can be used to ensure public safety and health, and to monitor and protect the environment. In the health sector, IoT devices can be used to assist in reporting or giving notifications of emergency cases and epidemics and can therefore help in the management of chronic diseases, disease prevention and control (Vermesan et al. 2013:75). IoT devices can be adopted in parking areas to monitor the available spaces in cities. They can also be installed in strategic structural buildings to monitor vibrations and material conditions, detect gas leakages in ind ustrial environments and to monitor energy consumption to identify cost and resources savings (Vermesan et al. 2013:33). Maximum precautions, continuous research and improvements are, however, needed to reduce cloud server security and privacy risks.

\section{Social media}

Social media are 'interactive computer-mediated technologies that facilitate the creation and sharing of information, ideas, and other forms of expressions via virtual communities and networks' (Wikipedia 2019). As social media services can be accessed on desktops, laptops and mobile phones, they provide a highly mobile interactive platform through which individuals or communities can communicate and interact.

Public information can be shared on social media platforms like Facebook and LinkedIn to promote information sharing and research in M\&E (Basheka et al. 2016:83). Social media can also be used to conduct formal scientific research. Many people willingly share their lives, challenges and progress openly on social media. By means of search platforms for research, unobtrusive research techniques are partly used to understand the social behaviours of people being studied without the respondents being aware that they are the subject 
of study (Auriacombe 2016:6). Unobtrusive research's strengths include its ease and cost-effectiveness of obtaining data about human interaction and reactions to events, amidst weaknesses in analysing huge amounts of data collected at regular intervals (Auriacombe 2016:12). Social media can also be used as a platform for education, strengthening commitments and creating social change (Basheka et al. 2016:83).

\section{Big data technologies}

Big data are defined as 'high volume, high velocity, and/or high variety information assets that require new forms of processing to enable enhanced decision making, insight discovery and process optimization' (Laney 2018 cited by Xing et al. 2018:172). Similarly, Kaplan and Haenlein (2018:16) describe big data as 'data sets characterized by huge amounts (volume) of frequently updated data (velocity) in various formats, such as numeric, textual or images/video (variety)'.

With the use of disruptive technologies, big data are being generated exponentially and analysing such data can assist in predicting various outcomes. In Africa, the use of mobile phones is exponentially increasing and big data from such devices can be used for prediction, mitigation and response. As presented above, in 2014 during an Ebola outbreak in Senegal, anonymised voice and text data from 150000 mobile phones were used to trace the patients' movements. The visualised information provided people's real-time movements, which were used to decide on the best locations to set up treatment centres and to restrict travel to contain the disease (Wall 2014).

In the $4 \mathrm{IR}$, data are seen as the major driver of growth and transformation, with the potential to influence the social, political, economic and service environment (Xing et al. 2018:173). With the technologies adopted in most services, data can be harvested for improvement of the health, agricultural and education sectors, to mention a few. In the public health sector, big data analytics could help improve health care, and accuracy could increase with the adoption of mHealth, eHealth and wearable technologies in Africa. The use of big data in the health care sector could, however, result in significant ethical challenges, such as risks to individual rights, privacy and autonomy, transparency and trust if not prudently handled (Xing et al. 2018:173).

\section{Implications of the Fourth Industrial Revolution technologies on public sector monitoring and evaluation in Africa}

Even with the highly anticipated opportunities from the extreme automation and digital transformations (cyberphysical systems) in the 4IR, the adoption of these disruptive innovations in African countries will have various consequences. Managing and effective adoption of these disruptive technologies call for deep integration, collaboration on long-term technology, and capability development in order mitigate the diverse and unpredictable effects on the public. Many innovations will require tailored legal, cultural, technological and economic infrastructure to enable efficient control and management because of their highly complex and interdependent nature. The enacted policies or legal guidelines need to be adaptive, inclusive, sustainable and human centred in order to address the increasing challenges of these new technological changes. Discussed below are some of the implications of the adaption of 4IR disruptive technologies in public sector M\&E in Africa. The discussion below is divided into two sections; the first challenge category focuses on M\&E personnel capacity, and the second on current M\&E systems.

\section{Information technology and data analytics skills}

As the 4IR is driven by digital data, it is imperative that for any data analysis to be conducted on disruptive technologies, one needs IT skills. For the public sector in Africa, this implies that all M\&E personnel in sectors that are to adopt the use of disruptive technologies will need IT to execute the required tasks. This move to a given extent shall threaten the jobs of some personnel for various reasons, for example, job redundancy and failure to acquire the required IT skills.

As discussed above, the use of big data to make decisions requires data analytics to obtain understanding, inferences and predictions from the data. While current M\&E methodologies rely on experimental designs that are viewed as rigorous assessment methods to ascertain the contribution of a given input towards an intended outcome variable, future big data analytics will focus on predictive analytics. These emerging two approaches, that is, experimental designs and predictive analytics, provide a broader understanding of the programme's impact. However, M\&E personnel need to have a broader understanding of data analytics. Below are some of the analyses that need to be appreciated by M\&E personnel.

\section{Mobile data analysis}

Mobile data analysis is defined by Xie et al. (2018) as:

... mining terabyte-level or perabyte-level data collected online and/or offline or from mobile users and wireless devices at the network-level or the app-level to discover unknown, latent, and meaningful patterns and knowledge. (p. 2)

With the decreasing prices of mobile phones and increasing mobile access to the Internet in Africa, mobile data analysis is an important methodology for improving decision-making in public sector service delivery. As people continuously use mobile Internet to satisfy their needs and requirements, huge volumes of big data are generated in terms of texts, images, voice and video. With the rapid growth in IoT gadgets and mobile devices, a large volume of data is automatically generated from machine nodes. Mobile data analysis is one of the techniques that can be employed for analysing huge 
quantities of mobile data, which would otherwise not be possible on a single machine. When the data generated from devices such as mobile phones, laptops and/or computers, GPS, smartcards and hand-held and biometric devices are analysed, they can generate insight that can be used for decision-making and evaluation.

Further follow-ups can be made through the use of calls, short message service (SMS), unstructured supplementary service data (USSD), mobile apps and interactive voice response systems (IVRSs). The use of these technologies can immensely improve transparency and accountability through better monitoring, sharing and use of data for real-time decision-making. The built-in logical flow and validation check help to improve data quality. A wide variety of data can be collected with such technologies, for example, the location, video and audio interactions and photos. Although the initial cost may be quite high, the subsequent costs only entail maintenance, and a large amount of money associated with traditional data collection can be saved.

\section{Machine learning}

Machine learning is defined as machines learning concepts using data and statistical analysis to predict, classify and input data as an output value (Choi \& Lee 2018:3). Xie et al. (2018:2) further explain that 'machine learning systems detect and classify objects, return the most relevant searching results, understand voice commands, and analyze using habits'. Machine learning is a branch of AI that allows machines to learn and adapt through experience.

Depending on the learning method with regard to the interaction with humans, machine learning can be divided into two categories, namely supervised and unsupervised learning (Choi \& Lee 2018:3). Supervised learning is used to predict the value of input data labelled by the human and is classified with the given label, while unsupervised learning is where patterns in a stream of inputs are performed without the need of a human and is often called a clustering process (Choi \& Lee 2018:3). Unsupervised learning branches off into deep learning, and this statistical analysis allows machines to teach themselves how to build models for pattern recognition. In circumstances where big data are obtained from multiple sources with dynamic and sparse values, deep learning techniques have been used to solve the problems with higher accuracy and hence obtaining better performance than conventional machine learning (Xie et al. 2018:5). Deep learning methods have the capability to learn patterns and relationships from hidden data layers where conventional methods like decision trees and support vector machines could fall short (Xie et al. 2018:3).

\section{Privacy and data security}

The issue of privacy and data security is contentious as it regards the adoption of some disruptive technologies for data collection. Using phones to track daily movements and communications among people, analysing people's moods on social media and using drones where satellites photograph private property every day create a worrying environment for privacy in a community. There is an increasing fear for trading of data, and this may spark conflicts and misunderstandings. Monitoring and evaluation personnel and departments have the challenge of ensuring that the collected data are safe from malicious acts; otherwise, it can put the individual or the entire country at risk or in a state of vulnerability.

\section{Autonomy, control and ethical concerns}

Data systems are a key supporting arm of M\&E systems as they are responsible for the generation of relevant, accurate and timely information that can be used in decision-making and for the improvement of programme design. However, with the adoption of some technologies, some key data may have strict and/or limited access and may therefore hinder extraction for analysis. Lack of critical data because of limited access can create a challenging situation for M\&E personnel and departments. The complexity of the ethical issues pertaining to the deployment of disruptive technologies is a huge challenge for the African public sector. With the boundaries between human subjects and technological objects virtually disappearing, it is vital to understand the ethical implications of these technologies and to address them in various perspectives so as to have a shared language and common methods for discourse, synthesis and coordination.

In addition to the above, the other challenges for public sector M\&E systems resulting from the adaption of disruptive technologies in Africa include the processes, approaches, techniques and tools employed in current M\&E systems that will be affected by the adoption of disruptive innovations and technologies in Africa.

\section{Obsolescence of the theory of change}

The 4IR also threatens the future use of models like the theory of change. Data scientists believe that the correlation of petabytes of data provides significant predictions that can be performed without the use of hypotheses (Anderson 2008 cited in United Nations [UN] Global Pulse 2016:30). This poses a challenge to evaluation designs and analysis because, in current evaluations, theoretical frameworks play a key guiding role in the selection of variables to measure to assess the impact or outcome of an intervention. However, important discussions need to be conducted to establish how the use of the appropriate theories can be incorporated into big data and data analytics in order to develop appropriate M\&E systems for Africa.

\section{Causality attribution approaches}

In big data analytics, predictive analytics are emphasised, which is in contrast to the experimental designs often employed in the current public sector M\&E. Experimental designs, which require the use of pre-tests and post-tests, are considered rigorous methodological approaches often deployed in 
quantitative methods, to ascertain the contribution of given inputs to intended outcomes. However, in big data analytics, Bayesian probability models are used to estimate and predict the probability of the occurrence of a set of given future events, using all the available data at a given time. This poses a challenge to ascertaining the contribution of a given programme's inputs to the observed changes. The two approaches could, however, provide a wealth of information for drawing recommendations to be used for decision-making.

\section{Data quality}

Using big data from disruptive technologies solely to draw evaluation recommendations may be quite misleading as such data have a significant selection bias. In current M\&E systems, substantial efforts are dedicated towards ensuring that the data to be used are unbiased and of high quality. The use of data from some disruptive innovations poses the challenge of having what can be termed an 'early warning signal' for crises to masquerade as the real data evaluators may use to draw conclusions on the impact of a given occurrence or programme or policy that may have serious consequences. It is therefore important in the 4IR to clarify what qualifies as a 'warning signal', to conduct research and to distinguish them from $M \& E$.

\section{Decision-making time horizon}

With digital big data available, the time taken to execute data analytics tasks is much faster compared to the duration of conventional M\&E data collection and data analysis. Considering the process and time taken to make management decisions in the current M\&E system, the results from data analytics can cause rapid decision-making, especially when the findings are reported online. The decision-making time can even be faster if the findings are accessed by the general public, who can exert pressure on management and/or governance. This is a challenge because decisions made because of pressure, with the mentality of 'we need to fix this right now', may not be good enough for the public or sustainable in the long run.

\section{Multi-stakeholder consultations}

The impact of disruptive innovations can spread very fast among the public. With the innovations' increasing penetration into the public, it is important that the users are well informed about the usefulness of the technologies but also that they understand the potential risks. The challenge lies in designing educational and training programmes that fully consider the majority of the potential risks, especially with regard to ethical and regulatory frameworks. Multistakeholder consultations are critical to addressing emerging concerns.

\section{Conclusion}

The 4IR presents immense benefits for public sector M\&E in Africa; however, the maximum effort must be made to address the diverse shortfalls of disruptive innovations and technologies. Predictions of the near future made by the United Nations indicate that most of the data sources used for programme M\&E will be generated passively through the use of these technologies (UN Global Pulse 2016:30). Currently, in disruptive technologies, there appears to be no clear distinction between research and M\&E. It should therefore not be assumed that when conducting data analytics for huge volumes of data, it automatically qualifies to provide a basis for programme or policy evaluation, because it may not be the case. Therefore, in order to maximise the benefits from the 4IR for public sector M\&E in Africa, the M\&E systems should be incorporated into the design of the technologies' data set-up. This purposely calls for critical discussions among M\&E specialists, technologists, economists, engineers and tech companies as a whole, especially for innovation geared at improving the well-being of the public. This will significantly enhance the quality, validity and reliability of the data captured by the technologies for evaluation purposes.

Additionally, maximising the opportunities in the 4IR requires multi-stakeholder efforts that call for an open mindset so as to fully explore the contributions from innovative ideas. This might require deep integration, or collaboration on long-term technology, so as to efficiently manage and control the highly complex and interdependent nature of the disruptive innovations. In the 4IR, it would be no surprise if some of the most powerful solutions to the challenges faced in Africa come from small start-ups or simpler collaborations rather than traditional large set-ups of public management. Therefore, emerging policies aimed at regulating or guiding the $4 \mathrm{IR}$ innovative technologies need to be adaptive, inclusive, sustainable and human centred in order to address the increasing challenges of these new technological changes.

Finally, it should be appreciated that as disruptive innovations and technologies are set to replace many of the tasks previously performed by humans, these applications also require humans to be operationalised. It is critical to further note that there are certain key tasks and responsibilities in M\&E that can never be completely replaced by machines because they need human understanding and consciousness to be performed in order to make the world a better place for everyone.

\section{Acknowledgements}

The authors are grateful for the kind support received from the editors and reviewers during the process of preparing this article for publication.

\section{Competing interests}

The authors declare that they have no financial or personal relationships that may have inappropriately influenced them in writing this article. 


\section{Authors' contributions}

Both authors contributed significantly to the collection of reading material and literature analysis. In addition, D.E.U. edited the final version of the manuscript and submitted it to the journal.

\section{Ethical consideration}

This article followed all ethical standards for carrying out research without direct contact with human or animal subjects.

\section{Funding}

This research received no specific grant from any funding agency in the public, commercial, or not-for-profit sectors.

\section{Data availability statement}

Data sharing is not applicable to this article as no new data were created or analysed in this study.

\section{Disclaimer}

The views and opinions expressed in this article are those of the authors and do not necessarily reflect the official policy or position of any affiliated agency of the authors.

\section{References}

Agence France-Presse, 2015, Robocops being used as traffic police in Democratic Republic of Congo, viewed 10 February 2019, from https://www.theguardian. $\mathrm{com} / \mathrm{travel} / 2015 / \mathrm{mar} / 05 /$ robocops-being-used-as-traffic-police-in-democraticrepublic-of-congo.

Al Jazeera, 2014, DR Congo recruits robots as traffic police, viewed 10 March 2019 from https://www.aljazeera.com/news/africa/2014/03/dr-congo-turns-robotscombat-traffic-2014320553142.

Auriacombe, C.J., 2013, 'In search of an analytical evaluation framework to meet the needs of governance', Journal of Public Administration 48(4.1), 715-729.

Auriacombe, C.J., 2016, 'Towards the construction of unobtrusive research techniques: Critical considerations when conducting a literature analysis', African Journal of Public Affairs 9(4), 1-19.

Banker, S., 2017, Drones deliver life-saving medical supplies in Africa, viewed 23 February 2019, from https://www.forbes.com/sites/stevebanker/2017/10/13/ drones-deliver-life-saving-medical-supplies-in-africa/.

Basheka, B.C., 2012, 'The paradigms of public administration re-examined: A reflection', Journal of Public Administration 47(1), 25-67.

Basheka, B.C., 2016, 'Evaluation capacity building (ECB) in Uganda: Trends, approaches, actors and the future', Administratio Publica 24(2), 95-121.

Basheka, B.C., Lubega, J.T. \& Baguma, R., 2016, 'Blended-learning approaches and the teaching of monitoring and evaluation programmes in African universities. Unmasking the UTAMU approach, African Journal of Public Affairs 9(4), 71-88.

Basheka, B.C. \& Byamugisha, A., 2015, 'The state of monitoring and evaluation (M\&E) as a discipline in Africa. From infancy to adulthood?', African Journal of Public Affairs 8(3), 75-95.

Brynjolfsson, E. \& McAfee, A., 2014, The second machine age: Work, progress, and prosperity in a time of brilliant technologies, W.W. Norton, New York.

Centre of Excellence in Financial Services, 2018, The impact of the $4^{\text {th }}$ Industrial Revolution on the South African financial services market, viewed 23 February 2019, from https://www.genesis-analytics.com/uploads/downloads/COEFS-The impactofthefourthindustrialrevolutiononfinancialservicesinSouthAfrica-final-1 FR.pdf.

Choi, D. \& Lee, K., 2018, 'An artificial intelligence approach to financial fraud detection under loT environment: A survey and implementation', Security and Communication Networks 2018, \#5483472, viewed 11 February 2019, from https://www.hindawi.com/journals/scn/2018/5483472/cta/.

Cloete, F., 2016, 'Developing an Africa-rooted programme evaluation approach', African Journal of Public Affairs 9(4), 55-70.

Davis, N., 2016, What is the Fourth Industrial Revolution?, viewed 10 April 2019 from https://www.wefprum.org/agends/2016/01/what-is-the-fourth-industrialrevolution/.
Deloitte, 2017, The Fourth Revolution is now: Are you ready? Future of operations, Deloitte LLP, London.

Farmer Line, n.d., Market-driven solutions empowering the entire agric value chain viewed 28 January 2019, from www.farmerline.co.

Floreano, D. \& Wood, R.J., 2015, 'Science, technology and the future of small autonomous drones', Nature 521(7553), 460-466.

Goldman, I., Byamugisha, A., Gounou, A., Smith, L., Ntakumba, S., Lubanga, T. et al. 2018, 'The emergence of government evaluation systems in Africa: The case of Benin, Uganda and South Africa', African Evaluation Journal 6(1), 11-25.

Gordon, R.J., 2016, The rise and fall of American growth: The U.S. standard of living since the Civil War, Princeton University Press, Princeton, NJ.

Hello Tractor, 2019, Connecting you to your tractor and your tractor to the world, viewed 01 April 2019, from https://www.hellotractor.com/home.

Idowu, T., 2018, African countries are importing robots and young people's jobs are at risk, viewed 13 February 2019, from https://www.cnn.com/2017/08/22/africa/ robots-in-africa/index.html.

Jarbandhan, D., 2017, 'Principles for public sector leadership in the Fourth Industria Revolution', Administratio Publica 25(4), 60-76.

Kaplan, A. \& Haenlein, M., 2018, 'Siri, Siri, in my hand: Who's the fairest in the land? On the interpretations, illustrations, and implications of artificial intelligence (abstract)', Business Horizon 62(1), 15-25.

Kimaro, J., Fourie, D. \& Tshiyoyo, M., 2018, 'The pathology of political conundrum and the utilisation of M\&E information in the public service in Africa', African Journal of Public Affairs 10(3), 102-117.

Kosner, A.W., 2012, Always early: Marc Andreessen's five big ideas that have shaped the Internet, viewed 28 March 2019, from https:/www.forbes.com/sites/ anthonykosner/2012/04/22/always-early-marc-andreessens-five-big-ideas-thathave-shaped-the-internet/.

Lakhiar, I., Jianmin, G., Syed, T.N., Chandio, F.A., Buttar, N.A. \& Qureshi, W.A., 2018 'Monitoring and control systems in agriculture using intelligent sensor techniques: A review of the aeroponic system', Journal of Sensors 2018,\#8672769, viewed 28 February 2019, from https://www.hindawi.com/journals/js/2018/8672769/cta/.

Marín, J., Parra, L., Rocher, J., Sendra, S., Lloret, J., Mauri, P.V. \& Masaguer, A., 2018 'Urban lawn monitoring in smart city environments', Journal of Sensors 2018, \#8743179, viewed 10 January 2019, from https://doi.org/10.1155/2018/8743179.

Martin, A., 2019, We could be sleepwalking into a new crisis: How should the business world prepare?, viewed 18 January 2019, from https://www.weforum.org/ agenda/2019/01/how-can-businesses-prepare-for-the-biggest-global-risks-in-2019/

Marwala, T. \& Hurwitz, E., 2017, Artificial intelligence and economic theories: Skynet in the market, Springer, Cham. https://doi.org/10.1007/978-3-319-66104-9

McKinsey Global Institute (MGI), 2017, Jobs lost, jobs gained: Workforce transitions in a time of automation, viewed 28 February 2019, from https://www.mckinsey. com/ $/$ media/mckinsey/featured $\% 20$ insights/Future $\% 20$ of $\% 200$ rganizations/ What $\% 20$ the $\% 20$ future $\% 20$ of $\% 20$ work $\% 20$ will $\% 20$ mean $\% 20$ for $\% 20$ jobs $\% 20$ skills $\% 20$ the $\% 20$ future $\% 20$ of\% $\%$ Work $\% 20$ will $\% 20$ mean $\% 20 f o r \% 20 j o b s \% 20$ skills $\% 2$
ashx.

Mokyr, J., Vickers, C. \& Ziebarth, N.L., 2015, 'The history of technological anxiety and the future of economic growth: Is this time different?', Journal of Economic Perspectives 29(3), 31-50.

MOOC List, n.d., Africa MOOCs and free online courses, viewed 25 February 2019, from https://www.mooc-list.com/tags/africa

Morgan, P., Baser, H. \& Morin, D., 2010, 'Developing capacity for managing public service reform: The Tanzania experience 2000-2008', Public Administration and Development Journal 30(2), 27-37.

Nsehe, M., 2016, Meet the man championing FinTech in Africa - Dave van Niekerk founder of MyBucks, viewed 01 May 2019, from https://www.forbes.com/sites/ mfonobongnsehe/2016/07/19/meet-the-man-championing-fintech-in-africadave-van-niekerk-founder-of-mybucks/amp/.

Nsengimana, J.P., 2018, How Africa wins the 4th Industrial Revolution, viewed 21 April 2019, from https://www.forbes.com/sites/startupnationcentral/2018/10/10/ how-africa-wins-the-4th-industrial-revolution/\#15b7f3122f37.

Peck, M.E., 2017, 'Blockchains: How they work and why they'Il change the world', IEEE Spectrum 54(10), 26-35.

Republic of Rwanda, 2016, Press release: University of Rwanda launches African centers of excellence to serve the region and beyond, viewed 23 February 2019 from http://mineduc.gov.rw/media/news/details-news/?tx_ttnews $\% 5 \mathrm{Btt}$ news $\% 5 \mathrm{D}=546 \& \mathrm{cHash}=1 \mathrm{~b} 323 \mathrm{c} 4 \mathrm{e} 285180 \mathrm{c} 410 \mathrm{~b} 343949 \mathrm{cfbfe} 5 \mathrm{~b}$.

Rifi, N., Agoulmine, N., Taher, N.C. \& Rachkidi, E., 2018, 'Blockchain technology: Is it a good candidate for securing loT sensitive medical data?', Wireless Communications and Mobile Computing 2018, \#9763937, viewed 25 April 2019, from https://www. hindawi.com/journals/wcmc/2018/9763937/.

Rifkin, J., 2012, The Third Industrial Revolution: How the Internet, green electricity, and 3-D printing are ushering in a sustainable era of distributed capitalism, viewed 21 April 2019, from https://www.worldfinancialreview.com/the-third-industrialrevolution-how-the-internet-green-electricity-and-3-d-printing-are-ushering-ina-sustainable-era-of-distributed-capitalism/.

Sethi, S., 2017, Vodafone India launches M-Pesa Pay for merchants and retailers, viewed 28 February 2019, from https://www.vodafone.com/content/index/what/ technology-blog/m-pesa-pay-india.html\#.

Schwab, K., 2016, The Fourth Industrial Revolution: What it means, how to respond viewed 25 February 2019, from https://www.weforum.org/agenda/2016/01/thefourth-industrial-revolution-what-it-means-and-how-to-respond/

Twiga, 2018a, Blockchain opens up Kenya's \$20 billion informal economy, viewed 01 March 2019, from https://twiga.ke/2018/06/29/blockchain-opens-up-in-kenya/ 
Twiga, 2018b, Our story, viewed n.d., from https://twiga.ke/twiga-story/

United Nations (UN) Global Pulse, 2016, Integrating big data into the monitoring and evaluation of development programmes, viewed 16 March 2019, from http:// unglobalpulse.org/sites/default/files/IntegratingBigData intoMEDP web UNGP. pdf.

Uwizeyimana, D. \& Basheka, B., 2017, 'The multidisciplinary, interdisciplinary and transdisciplinary nature of public administration. A methodological challenge?', African Journal of Public Affairs 9(9), 1-28.

Vermesan, O., Friess, P., Guillemin, P., Sundmaeker, H., Eisenhauer, M., Moessner, K. et al., 2013, 'Internet of things strategic research and innovation agenda', in O. Vermesan \& P. Friess (eds.), Internet of things: Converging technologies for smart environments and integrated ecosystems, 7-168, River Publishers, Gistrup.

Vodafone, 2017, Vodafone marks 10 years of the world's leading mobile money service, M-Pesa, viewed 16 March 2019, from https:///www.vodafone.com/ content/index/media/vodafone-group-releases/2017/m-pesa-10.html

Waldron, D. \& Amusin, E., 2017, How digitizing agricultural input payments in rural Kenya is tackling poverty: The case of One Acre Fund, viewed 25 February 2019 , from https://www.betterthancash.org/tools-research/case-studies/digitizingagricultural-input-payments-in-rural-kenya.

Wall, M., 2014, Ebola: Can big data analytics help contain its spread?, viewed 22 February 2019, from http://www.bbc.com/news/business-29617831.

Wikipedia, 2019, Social media, viewed n.d., from https://en.wikipedia.org/wiki/ Social_media

World Economic Forum (WEF), 2017, Impact of the Fourth Industrial Revolution on supply chains, viewed 30 April 2019, from http://www3.weforum.org/docs/WEF Impact_of_the_Fourth_Industrial_Revolution_on_Supply_Chains_.pdf.
World Health Organization (WHO), 2018, Ebola virus disease, viewed 30 April 2019, from https://www.who.int/news-room/fact-sheets/detail/ebola-virus-disease.

Wotela, K., 2017, 'A proposed monitoring and evaluation curriculum based on a model that institutionalizes monitoring and evaluation', African Evaluation Journal 1(1), $1-8$.

Xie, J., Song, Z., Li, Z., Zhang, Y., Yu, H., Zhan, J. et al., 2018, 'A survey on machine learning-based mobile big data analysis: Challenges and applications', Wireless Communications and Mobile Computing 2018, \#8738613, viewed 23 February 2019, from https://www.hindawi.com/journals/wcmc/2018/8738613/.

Xing, B., Marwala, L. \& Marwala, T., 2018, 'Adopt fast, adapt quick: Adaptive approaches in the South African context (Chapter 8)', in N.W. Gleason (ed.), Higher education in the era of the Fourth Industrial Revolution, pp. 171-206, Macmillan, Singapore.

Xing, B. \& Marwala, T., 2017, 'Implications of the fourth industrial age for higher education', The Thinker 73, 10-15, viewed 20 February 2019, from http://www. thethinker.co.za/resources/73\%20xing\%20and\%20marwala.pdf.

Yesmin, S., Paul, A.T. \& Uddin, M., 2019, 'bKash: Revolutionizing mobile financial services in Bangladesh?', in A. Sikdar \& V. Pereira (eds.), Business and management practices in South Asia: A collection of case studies, pp. 125-148, Macmillan, Singapore.

Zheng, R., Jiang, J., Hao, X., Ren, W., Xiong, F. \& Ren, Y., 2019, 'bcBIM: A blockchainbased big data model for BIM modification audit and provenance in mobile cloud', Mathematical Problems in Engineering 2019, \#5349538, viewed 13 March 2019, from https://www.hindawi.com/journals/mpe/2019/5349538/.

Zipline, n.d., Lifesaving deliveries by drone, viewed 20 April 2019, from https:// flyzipline.com/uploads/Zipline $\% 20$ Fastest $\% 20$ Drone $\% 20$ Press $\% 2$ Release.pdf. 